\title{
Characterisation of the tryptophan synthase alpha subunit in maize
} Verena Kriechbaumer ${ }^{1}$, Linda Weigang ${ }^{2}$, Andreas Fießelmann"1, Thomas Letzel $^{2}$, Monika Frey ${ }^{1}$, Alfons Gierl ${ }^{1}$ and Erich Glawischnig*1

\author{
Address: ${ }^{1}$ Lehrstuhl für Genetik, Technische Universität München, D-85350 Freising, Germany and ${ }^{2}$ Analytische Forschungsgruppe des Lehrstuhls \\ für Chemie der Biopolymere, Technische Universität München, D-85350 Freising, Germany \\ Email: Verena Kriechbaumer - verena.kriechbaumer@wzw.tum.de; Linda Weigang - L.Weigang@lrz.tu-muenchen.de; \\ Andreas Fießelmann - a.fiesselmann@wzw.tum.de; Thomas Letzel - T.Letzel@lrz.tu-muenchen.de; Monika Frey - monika.frey@wzw.tum.de; \\ Alfons Gierl - gierl@wzw.tum.de; Erich Glawischnig* - egl@wzw.tum.de \\ * Corresponding author
}

Published: 22 April 2008

BMC Plant Biology 2008, 8:44 doi:1 0.1 I86/I47/-2229-8-44

This article is available from: http://www.biomedcentral.com/I47I-2229/8/44

(c) 2008 Kriechbaumer et al; licensee BioMed Central Ltd.

This is an Open Access article distributed under the terms of the Creative Commons Attribution License (http://creativecommons.org/licenses/by/2.0), which permits unrestricted use, distribution, and reproduction in any medium, provided the original work is properly cited.

\begin{abstract}
Background: In bacteria, such as Salmonella typhimurium, tryptophan is synthesized from indole3-glycerole phosphate (IGP) by a tryptophan synthase $\alpha \beta \beta \alpha$ heterotetramer. Plants have evolved multiple $\alpha$ (TSA) and $\beta$ (TSB) homologs, which have probably diverged in biological function and their ability of subunit interaction. There is some evidence for a tryptophan synthase (TS) complex in Arabidopsis. On the other hand maize (Zea mays) expresses the TSA-homologs BXI and IGL that efficiently cleave IGP, independent of interaction with TSB.

Results: In order to clarify, how tryptophan is synthesized in maize, two TSA homologs, hitherto uncharacterized ZmTSA and ZmTSAlike, were functionally analyzed. ZmTSA is localized in plastids, the major site of tryptophan biosynthesis in plants. It catalyzes the tryptophan synthase $\alpha$-reaction (cleavage of IGP), and forms a tryptophan synthase complex with ZmTSBI in vitro. The catalytic efficiency of the $\alpha$-reaction is strongly enhanced upon complex formation. A $160 \mathrm{kD}$ tryptophan synthase complex was partially purified from maize leaves and ZmTSA was identified as native $\alpha$ subunit of this complex by mass spectrometry. ZmTSAlike, for which no in vitro activity was detected, is localized in the cytosol. ZmTSAlike, BXI, and IGL were not detectable in the native tryptophan synthase complex in leaves.
\end{abstract}

Conclusion: It was demonstrated in vivo and in vitro that maize forms a tryptophan synthase complex and ZmTSA functions as $\alpha$-subunit in this complex.

\section{Background}

Tryptophan is an essential amino acid for human nutrition. In kernels of cereals, e.g. maize (Zea mays), the tryptophan content is low, limiting the nutritional value. Significant effort is made to breed maize lines with enhanced tryptophan content $[1,2]$. In addition to its function as protein component, plants utilize tryptophan as precursor of a large variety of secondary metabolites like terpenoid indole alkaloids, indole glucosinolates, and indolic phytoalexins (reviewed in: $[3,4]$ ). Of special importance is the tryptophan-derived plant hormone indole-3-acetic acid (IAA), which is involved in numerous processes, including embryo development, apical dominance, and tropisms $[4,5]$. These essential functions of tryptophan emphasize the need to understand its synthesis in plants in more detail. 
In bacteria, such as Escherichia coli and Salmonella typhimurium, tryptophan is synthesized from indole-3-glycerol phosphate (IGP) by a tryptophan synthase (TS) complex [6]. IGP is cleaved by the TS $\alpha$-subunits (TSA) to indole and glyceraldehyde-3-phosphate ( $\alpha$-reaction). Then indole is transported via a $30 \AA$ intermolecular tunnel to the tryptophan synthase $\beta$-subunits (TSB) that catalyze the condensation of indole and serine ( $\beta$-reaction) to tryptophan (Figure 1; for review, see $[7,8]$ ). This substrate channelling ensures that indole does not escape from the enzyme complex. The reaction mechanism of this bacterial $\alpha \beta \beta \alpha$ complex has been studied in great detail. The $\alpha$ and $\beta$-subunits interact in a highly cooperative manner and regulate each other reciprocally by allosteric interactions. In addition, alternative TSBs that are highly active, independent of interaction with the unique TSA, are expressed in some prokaryotes [9]. In fungi interaction of TSA and TSB is obligate as both functions are present on a single polypeptide $[9,10]$.

The picture is more complex in higher plants. The homologs of the bacterial TSA and TSB genes are generally duplicated, e.g. the Arabidopsis thaliana genome contains two putative TSA and four putative TSB genes. Currently the role of these different isoforms is not fully understood. Functional relevance of AtTSA1 (At3g54640) and AtTSB1 (At5g54810) was demonstrated by the facultative tryptophan auxotroph mutants $\operatorname{trp} 3$ and $\operatorname{tr} p 2$, respectively $[11,12]$. AtTSA1 and AtTSB1 are both localized in the plastid $[11,13,14]$. Based on immunoaffinity chromatography it was strongly suggested that the two proteins form an active $\alpha \beta$ complex [14]. However, it is not known whether formation of such complexes is a general phenomenon in plants.

Among the cereals most information on TSA and TSB homologs is available for maize: Two highly similar TSB genes (ZmTSB1 and ZmTSB2) have been identified, shar- ing 96\% identity on the mature protein level. ZmTSB1 and $Z m$ TSB2 are functionally redundant active TSB enzymes. While single mutations in either gene do not affect tryptophan synthesis, the double mutant orange pericarp (orp1 $=Z m t s b 1$, orp2 $=Z m t s b 2)$ is tryptophan auxotroph $[15,16]$. Four TSA homologs are present: BX1, IGL, ZmTSAlike [17], and ZmTSA (this work). BX1 is essential for providing indole as precursor of the natural pesticide 2,4-dihydroxy-7-methoxy-2H-1,4-benzoxazin-3(4H)-one

(DIMBOA) [18]. The 3-dimensional BX1 structure has been determined and shown to be very similar to the active conformation of bacterial TSAs [19]. Igl transcription is triggered by insect feeding and IGL provides indole as a volatile signal for parasitic wasps $[17,20]$. BX1 and IGL efficiently cleave IGP to form indole, while the activity of bacterial TSA subunits is dependent on the interaction with a $\beta$-subunit $[17,18]$. These enzymatic properties, their specific transcriptional regulation, and the lack of growth defects of $b x 1$ and igl mutant plants suggested that additional TSA-homologs are involved in tryptophan biosynthesis.

In this study we aimed to identify the TSA homolog from maize that is involved in tryptophan biosynthesis. ZmTSA is catalytically active and interaction of ZmTSA with a $\beta$ subunit strongly enhances the catalytic efficiency of the $\alpha$ reaction. A protein purification strategy was applied to obtain direct evidence that angiosperms, similarly to bacteria, form a tryptophan synthase complex.

\section{Methods}

\section{Plant material and growth conditions}

The following maize (Zea mays) lines were analyzed: B73 (wildtype), bx1 mutant [21], and the tsb mutants (orp1 +/ orp1 orp2) and (orp1 orp2/+ orp2) [15] that were kindly provided by the maize genetic stock center. Seedlings were germinated in a beaker rolled in wet filter paper $(603 / \mathrm{N}$, $75 \mathrm{~g} \mathrm{~m}^{-2}$, Sartorius) at $28^{\circ} \mathrm{C}$ in the dark and after three

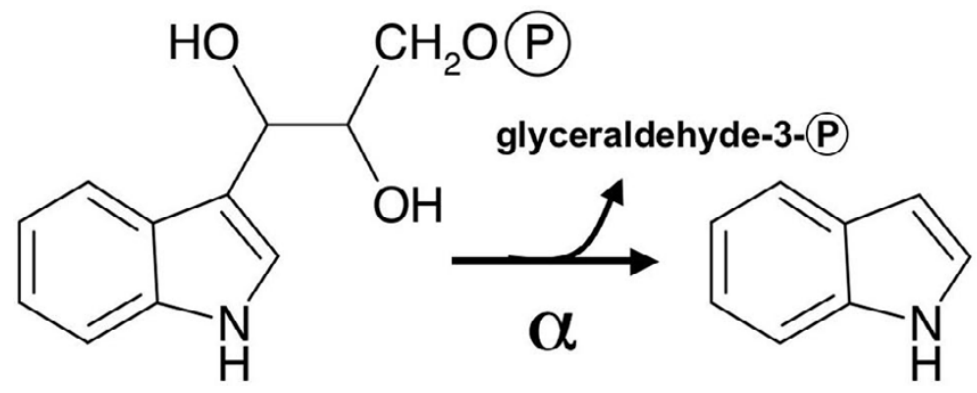

indole-3-glycerol phosphate

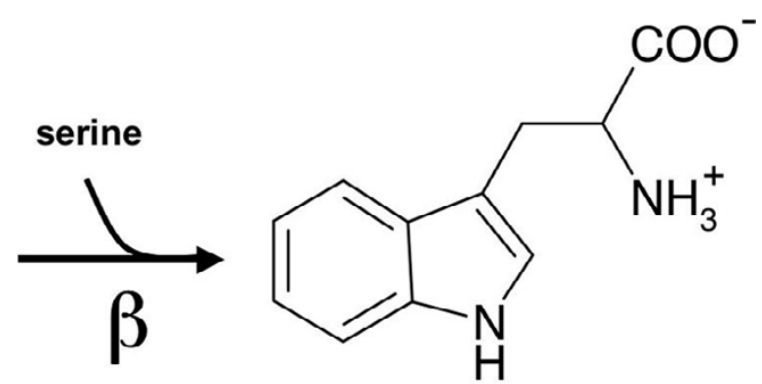

tryptophan

\section{Figure I}

General scheme of the tryptophan synthase reaction. Indole, which is formed from IGP by the $\alpha$-subunits is channelled to $\beta$-subunits, which synthesize tryptophan from indole and serine. 
days the seedlings were transferred to soil and incubated in a Heraeus HPS 2000 growth chamber (light: $100 \mu \mathrm{mol}$ $\left.\mathrm{m}^{-2} \mathrm{~s}^{-1} ; 16 \mathrm{~h} / \mathrm{d}\right)$.

\section{Identification of ZmTSA and heterologous expression of standard proteins}

For isolation of cDNAs a library prepared from 12 day old seedlings, line $b x 1$ [21] was used [17]. A ZmTSAlike cDNA clone was isolated based on the genomic sequence [17] and confirmed to be full-length by RACE. The ZmTSA cDNA was cloned [GenBank:EU334442] based on the EST AY107255 (gene bank) and the EST-TUG Zmtuc03-0811.4557 (maize genomic database) and confirmed to be full-length based on the genomic sequence. ZmTSA and $Z m$ TSAlike were analyzed for plastid targeting sequences using the programs "TargetP" and "iPSORT" $[22,23]$.

BX1 and IGL expression and purification have been described previously $[17,18]$. For heterologous expression of ZmTSA and ZmTSAlike, an NdeI/BglII-fragment, for $Z m T S B 1$ expression an NdeI/BamHI-fragment of the coding sequence excluding plastid-targeting sequences was amplified by PCR. The following primers were used: ZmTSA: GCATATGCCGCGCAGCATCTCCG, TCTTACGC TCTTTGCTAACGAAAATGG; ZmTSAlike: CGCATATGGC CAACGGCGGCG， GGGAGTGAGATCTGCTCACGGC; ZmTSB1: CATATGGCGGCCTCCCCCGCTGCCG, CTCGGATCCAGCCCTCCTCTCCGGTG. The coding sequences were cloned into pET28a His-tag vector, heterologously expressed, and purified under native conditions by Histag affinity purification via Ni-NTA agarose according to the manufacturers' suggestions (Qiagen, Hilden, Germany).

For the detection of TSA/TSB complex formation in vitro, size exclusion chromatography (HiLoad ${ }^{\mathrm{TM}} 16 / 60$ Super$\mathrm{dex}^{\mathrm{TM}} 200$ prep grade, Amersham Biosciences, Little Chalfont, UK) was performed using $100 \mathrm{mM}$ Tris- $\mathrm{HCl}$, $\mathrm{pH}$ 8.0, $100 \mathrm{mM} \mathrm{KCl}$ at $0.5 \mathrm{ml} \mathrm{min}^{-1}$ and $20^{\circ} \mathrm{C}$. The column was calibrated using the protein standards cytochrome c (12.4 $\mathrm{kD})$, carbonic anhydrase (29 kD), bovine albumin (66 $\mathrm{kD})$, alcohol dehydrogenase (150 kD), and $\beta$-amylase (200 kD).

\section{Transcription analysis}

For detection of ZmTSA and ZmTSAlike expression total RNA was isolated from the wildtype line B73 and quantitative real time PCR was carried out using the LightCycler/ Syb ${ }^{\circledast}$-Green dye system (Roche, Mannheim, Germany) with the following primer pairs: ZmTSA: CACTGCTGGAGACCCTGACT, GGTTCATGGCAATGCGGCCT; ZmTSAlike: CCACAAAGGCAGCGCTCGGAGGTG, GCCTCGCTC CTCAGCAACGTCGTCT; GAPDH C: GCTAGCTGCACCACAAACTGCCT, TAGCCCCACTCGTTGTCGTACCA.
Tissues analyzed are the following: leaf from $12 \mathrm{~d}$ old plants ( $12 \mathrm{~d}$ leaf), $12 \mathrm{~d}$ leaf methyl jasmonate treated, 12 d leaf elicitor treated [20], $4 \mathrm{~d}$ shoot dark grown, $6 \mathrm{~d}$ shoot dark grown, $6 \mathrm{~d}$ shoot light grown, 3 week root, 10 week crown root, 8 week stem, 10 week leaf, husk, silk, cob, tassel, kernel 1 week after pollination (wap), kernel 3 wap.

\section{Tryptophan synthase activity assays}

Plant protein fractions $(200 \mu \mathrm{g})$ or purified recombinant enzyme $(2 \mu \mathrm{g})$ were incubated $3 \mathrm{~h}$ for plant protein, $5 \mathrm{~min}$ for recombinant proteins, respectively, at $30^{\circ} \mathrm{C}$, in $80 \mathrm{mM}$ potassium phosphate buffer, $\mathrm{pH} 8.2$ containing the following substrates: $\alpha$-reaction: $100 \mu \mathrm{M}$ IGP [24]; $\beta$-reaction: $50 \mu \mathrm{M}$ indole, $60 \mathrm{mM}$ L-serine, $50 \mu \mathrm{M}$ pyridoxal phosphate; $\alpha \beta$-reaction: $100 \mu \mathrm{M}$ IGP, $60 \mathrm{mM}$ L-serine, 50 $\mu \mathrm{M}$ pyridoxal phosphate, concentration ranges were analyzed for determination of kinetic parameters.

The products indole and tryptophan were quantified by HPLC (RP-column: LiChroCART 125-4, RP-18, $5 \mu \mathrm{m}$; Merck, West Point, PA) using diode array (PDA-100, Dionex, Idstein, Germany) and fluorescence detection $\left(\mathrm{RF}-10 \mathrm{~A}_{\mathrm{XL}}\right.$, Shimadzu, Duisburg, Germany; excitation: $285 \mathrm{~nm}$, emission: $360 \mathrm{~nm}$ ). The mobile phase was delivered with a flow rate of $1 \mathrm{ml} \mathrm{min}^{-1}$ with an initial mixture of $15 \%(\mathrm{v} / \mathrm{v}) \mathrm{MeOH}$ in $0.3 \%(\mathrm{v} / \mathrm{v}) \mathrm{HCOOH}$ followed by a 15 min linear gradient to $100 \% \mathrm{MeOH}$.

\section{Plant protein purification}

Leaf tissue $(50 \mathrm{~g})$ was homogenized in liquid nitrogen and extracted in $5 \mathrm{ml} 50 \mathrm{mM}$ Tris- $\mathrm{HCl}, \mathrm{pH}$ 8.0, containing 10 mM EDTA, 5 mM DTE, 1 mM PMSF, and 10\% Polyclar AT (Serva, Heidelberg, Germany) and centrifuged $20 \mathrm{~min}$ at $10.000 \mathrm{~g}\left(4^{\circ} \mathrm{C}\right)$. The supernatant was subjected to an anion exchange column (MonoQ HR 5/5, Amersham) equilibrated with $100 \mathrm{mM}$ Tris- $\mathrm{HCl}, \mathrm{pH} 8.0,10 \mathrm{mM}$ EDTA, $5 \mathrm{mM}$ DTE, $100 \mathrm{mM} \mathrm{NaCl}$ at $4{ }^{\circ} \mathrm{C}$. The column was then washed with $10 \mathrm{Vol}$ of the same buffer and eluted with $100 \mathrm{mM}$ Tris-HCl, pH 8.0 containing $10 \mathrm{mM}$ EDTA, $5 \mathrm{mM}$ DTE, and $1 \mathrm{M} \mathrm{NaCl}$ in a $20 \mathrm{Vol}$ linear gradient. Fractions around $450 \mathrm{mM} \mathrm{NaCl}$ showed TS activity and were subjected $\left(0.5 \mathrm{ml} \mathrm{min}^{-1}, 20^{\circ} \mathrm{C}\right)$ to gel permeation chromatography (HiLoad ${ }^{\mathrm{TM}} 16 / 60$ Superdex $^{\mathrm{TM}} 200$ prep grade, Amersham, equilibrated with $100 \mathrm{mM}$ Tris-HCl, pH 8.0 including $100 \mathrm{mM} \mathrm{KCl}$ ). The column was eluted with the same buffer $\left(180 \mathrm{ml}, 0.5 \mathrm{ml} \mathrm{min}^{-1}\right)$. $1 \mathrm{ml}$ fractions were collected and tested for $\alpha$ - and $\beta$-activity. The 54 to $56 \mathrm{ml}$ fractions were precipitated by addition of $10 \%$ TCA, redissolved in $10 \mu \mathrm{l} 10 \mathrm{mM}$ Tris-HCl, pH 6.8, $20 \mathrm{mM}$ DTT, 2\% $(\mathrm{w} / \mathrm{v})$ SDS, $0.01 \%(\mathrm{w} / \mathrm{v})$ bromphenol blue, $10 \%(\mathrm{w} / \mathrm{v})$ glycerol, and subjected to SDS-PAGE.

After fixation for $>2 \mathrm{~h}$ with a $40 \%$ (v/v) $\mathrm{MeOH} / 10 \%$ (v/ v) HOAc solution and washing in water for $2 \times 10 \mathrm{~min}$ the gels were stained over night with Coomassie dye $(0.08 \%$ 
(w/v) Coomassie Brilliant Blue G250, 1.6\% (w/v) orthophosphoric acid, $8 \%(\mathrm{w} / \mathrm{v})\left(\mathrm{NH}_{4}\right)_{2} \mathrm{SO}_{4}, 20 \%$ (v/v) $\mathrm{MeOH})$ and destained in $1 \%(\mathrm{v} / \mathrm{v})$ HOAc [25]. The protein bands between 25 and $60 \mathrm{kD}$ were cut out and the gel piece was further destained in a thermo mixer with water $\left(2 \times 30 \mathrm{~min} 37^{\circ} \mathrm{C}\right), 200 \mathrm{mM} \mathrm{NH} \mathrm{HCO}_{3}, \mathrm{pH} 7.8(2 \times 30$ $\left.\min 37^{\circ} \mathrm{C}\right)$, and $50 \%$ acetonitrile $(\mathrm{ACN})(2 \times 5 \mathrm{~min}$ $37^{\circ} \mathrm{C}$ ). The gel slice was shrunk in $100 \% \mathrm{ACN}$, the liquid supernatant was removed and the gel dried in a SpeedVac for $5 \mathrm{~min}$.

\section{Identification of tryptophan synthase protein components: sample preparation}

Tryptic digestion: $100 \mu \mathrm{l}$ trypsin solution (200 ng $\mu^{-1}$, Promega) were directly pipetted on the gel piece, incubated for $10 \mathrm{~min}$ on ice to allow the trypsin to move into the gel and then covered with $500 \mu \mathrm{l} 25 \mathrm{mM} \mathrm{NH}_{4} \mathrm{HCO}_{3}$ followed by $16 \mathrm{~h}$ incubation at $37^{\circ} \mathrm{C}$. Digestion was stopped by adding $50 \mu \mathrm{l}$ of $10 \%$ trifluoroacetic acid and the supernatant was transferred to a new tube. Peptides were extracted by consecutive basic and acid extraction. Basic extraction: $50 \mu \mathrm{l} 40 \mathrm{mM} \mathrm{NH}_{4} \mathrm{HCO}_{3}$ were added to the gel, shaken for $30 \mathrm{~min}$ at $37^{\circ} \mathrm{C}$, and the supernatant transferred to a new tube. The same incubation followed after addition of $50 \mu \mathrm{l} \mathrm{ACN}$. Both steps were repeated and the supernatants pooled. Acid extraction: The gel piece was extracted twice in $50 \mu \mathrm{l} 5 \%(\mathrm{v} / \mathrm{v}) \mathrm{HCOOH}$ for $30 \mathrm{~min}$. The gel piece was shrunk twice in $50 \mu \mathrm{l} \mathrm{ACN}$. All the collected supernatants were pooled, dried in a SpeedVac and dissolved in $100 \mu \mathrm{l} 20 \mathrm{mM}$ ammonium acetate buffer, $\mathrm{pH}$ 7.4, 10\% (v/v) ACN, 5 mM DTT.

A further step of digestion was performed in solution (10 $\mu \mathrm{l}$ trypsin solution, $200 \mathrm{ng} \mathrm{l}^{-1}, 8 \mathrm{~h}, 37^{\circ} \mathrm{C}$ ) to apply a maximum amount of hydrolyzed peptides without miscleavage. Latter is important for a reproducible identification of qualifying peptides.

\section{Liquid chromatography - mass spectrometry (LC-MS)}

An Agilent micro HPLC system (series 1100, Waldbronn, Germany) consisting of a quaternary capillary pump (G1376A), a degasser unit (G1379A), an auto sampler (G1377A), and a column in a thermostat set to $40^{\circ} \mathrm{C}$ (G1316A) was used in combination with a single time-offlight mass spectrometer (LC/MSD TOF, Agilent Technologies, Santa Clara, USA). The chromatographic separation was performed with a Zorbax SB C18 column $(150 \times 0.5$ $\mathrm{mm}$ i.d.; $5 \mu \mathrm{m}$, Agilent Technologies, Santa Clara, USA) by $8 \mu \mathrm{l}$ sample injections. Prior to injection, the trypsinized protein samples were mixed with $200 \mu \mathrm{l} 20 \mathrm{mM} \mathrm{NH}_{4} \mathrm{Ac}$, $10 \% \mathrm{ACN}(\mathrm{v} / \mathrm{v}), 5 \mathrm{mM}$ DTT, pH 7.4, sonified for $15 \mathrm{~min}$, filtrated via HV filter, and stored in an autosampler vial. The HPLC separation flow rate was $50 \mu \mathrm{l} \mathrm{min}^{-1}$. At the beginning of each chromatographic run, the composition of the mobile phase was kept at 95\% $20 \mathrm{mM} \mathrm{NH}_{4} \mathrm{Ac} / 5 \%$
ACN (v/v), following a gradient to $20 \% 20 \mathrm{mM} \mathrm{NH}_{4} \mathrm{Ac} /$ $80 \% \mathrm{ACN}(\mathrm{v} / \mathrm{v})$ within $5 \mathrm{~min}$ and this final value was held for $15 \mathrm{~min}$.

MS measurements were performed in positive ionization mode with the mass spectrometer equipped by an ESI source. The applied MS parameter were as follows: $350^{\circ} \mathrm{C}$ drying gas temperature, $420 \mathrm{Lh}^{-1}$ drying gas flow rate, 20 psig nebulizer gas pressure, $4000 \mathrm{~V}$ capillary voltage, $60 \mathrm{~V}$ skimmer voltage and $215 \mathrm{~V}$ fragmentor voltage. The massrange was set to $150-3200 \mathrm{~m} / \mathrm{z}$ and data acquisition was 0.88 cycles/sec. The drying gas nitrogen was supplied by a nitrogen generator (nitrogen purity $\geq 99.5 \%$, Domnick Hunter, Willich, Germany). The ChemStation software (Rev. B.01.01, Agilent, Waldbronn, Germany) was used for system control and the Analyst QS software (LC-MS TOF Software, Ver. A.01.00 (B663), June, 2004) for the data acquisition.

\section{Expression of ZmTSA- and ZmTSAlike-GFP-fusion proteins}

To construct vectors for expression of GFP-fusion protein [26], the stop codon of the ZmTSA coding sequence was replaced by a BglII restriction site, using the following primers: 5'-CGACTACACCAAATGAAAGAATGGAG-3' (forward), 5'-CTCGAGAGATCTGGCAATGCGGCCTTCAGG-3' (reverse). The full size ZmTSA cDNA fragment, in which the stop codon was eliminated, was then cut from the vector with EcoRI/BglII and cloned into the EcoRI/BamHI sites of the pEZS-NL vector (D. Ehrhardt, Carnegie Institution). The ZmTSA-eGFP chimera was cut with EcoRI, blunted, cut with XbaI, and cloned into the SmaI/XbaI sites of the PvuII-deletion of $\mathrm{pPCV}_{\mathrm{E}} 35_{\mathrm{E}}$ plant transformation vector. The same strategy was used for the construction of the ZmTSAlike-eGFP chimeric cDNA, with the primer pair: CAAGCTGGCATACATGGAC/GGTACCAGATCTGGCATAGCAGCCTTCATA.

\section{Transfection of maize protoplasts and confocal microscopy}

Maize LG22 seedlings were grown on an $8 \mathrm{~h}$ dark, $20^{\circ} \mathrm{C} /$ $16 \mathrm{~h}$ light, $26^{\circ} \mathrm{C}$ regime for 6 to 8 days and were then transferred to the dark for 3 days. Protoplasts were isolated from the second true leaves essentially as described previously $[27,28]$. Digestion was performed in $1 \%(\mathrm{w} / \mathrm{v})$ cellulase R10, 0,5\% (w/v) Macerozyme R10 (both from Yakult Honsha), 0.6 M mannitol, 10 mM MES, pH 5.7, 1 $\mathrm{mM} \mathrm{CaCl}_{2}$ for $2 \mathrm{~h}$ at $28^{\circ} \mathrm{C}$ on a rotating shaker $(40 \mathrm{rpm})$. After filtration through a $65-\mu \mathrm{m}$ nylon mesh, the protoplasts were collected by 3 min centrifugation at $200 \mathrm{~g}$, followed by centrifugation at $100 \mathrm{~g}$ in floating solution $(25 \%$ sucrose (w/v), $10 \mathrm{mM} \mathrm{MES,} 20 \mathrm{mM} \mathrm{KCl}$ ). Floating protoplasts were washed in $0.6 \mathrm{M}$ mannitol, $4 \mathrm{mM}$ MES, $20 \mathrm{mM}$ $\mathrm{KCl}$ and counted. Electroporation was performed with 2.5 $\times 10^{5}$ protoplasts and $40 \mu \mathrm{g}$ of each plasmid in $300 \mu \mathrm{l} 4$ 
mM MES-KOH, pH 5.7, 0.6 M mannitol, $20 \mathrm{mM} \mathrm{KCl}$. Transformed protoplasts were incubated in the dark at $25^{\circ} \mathrm{C}$ for $20 \mathrm{~h}$ in $4 \mathrm{mM}$ MES-KOH, pH 5.7, $0.6 \mathrm{M}$ mannitol, $4 \mathrm{mM} \mathrm{KCl}$.

Confocal microscope images were taken using an Olympus FV1000 confocal laser microscope with a $40 \times$ water objective. The excitation wavelength for eGFP detection was $488 \mathrm{~nm}$.

\section{Results}

\section{Isolation of ZmTSA}

In maize, four genes encoding TSA homologs are present. $B x 1, I g l$, and ZmTSAlike have been described previously $[17,18]$. A search of the GeneBank and maize genomic database (see Availability and requirements section for $\mathrm{URL}$ ) revealed putative TSA sequences, which do not constitute alleles of Bx1, Igl, or ZmTSAlike. These sequences, partly represented by the Tentative Unique Gene (TUG) Zmtuc03-08-11.4557, correspond to a new gene, now designated ZmTSA. ZmTSA is located on chromosome 7 (contig AC191027, GeneBank). A full-length ZmTSA cDNA clone was isolated [GenBank:EU334442]. Most plant TSAs have divergent $\mathrm{N}$-terminal sequences that have no counterpart in bacteria and represent transit peptides for plastid import. When this variable part is excluded from the analysis, $Z m$ TSA is $63 \%$ identical to BX1, $67 \%$ to IGL, and $72 \%$ to $Z m$ TSAlike on protein level, respectively [for an alignment, see Additional file 1].

\section{Expression and subcellular localization}

For a further characterization of the closely related genes ZmTSA and ZmTSAlike their transcription levels were determined by RT-PCR in different tissues and developmental stages. ZmTSA and ZmTSAlike transcripts were detected in all 16 tissues analyzed [see Additional file 2] and generally, ZmTSA was the predominant isoform expressed. The average transcript levels relative to GAPDH in these preparations were determined as $1.80 \pm 0.93 \mathrm{fg} \mathrm{fg}$ 1 for $Z m$ TSA and $0.20 \pm 0.15 \mathrm{fg} \mathrm{fg}^{-1}$ for $Z m$ TSAlike. The virtually homogeneous expression of ZmTSA and ZmTSAlike qualifies them as candidates to function in tryptophan biosynthesis in maize. In contrast, $B x 1$ is predominantly transcribed in seedlings and $I g l$ is specifically induced in response to herbivore attack $[17,18,20]$.

There is a number of data suggesting that plant tryptophan biosynthesis is predominantly localized in the plastids [13,29]. ZmTSA and ZmTSAlike were analyzed in silico for putative targeting sequences using "TargetP" and "iPSORT" [22,23]. ZmTSA was predicted to be plastid localized, while ZmTSAlike, 45 amino acids shorter at the $\mathrm{N}$-terminus, was expected to be retained in the cytoplasm.
To obtain experimental evidence, plasmids conferring expression of $Z m T S A$ - and $Z m$ TSAlike-GFP fusion proteins were transformed into maize protoplasts. GFP and chlorophyll autofluorescence were analyzed by confocal microscopy (Figure 2). In case of ZmTSA GFP fluorescence coincided with the chlorophyll autofluorescence of the chloroplasts (Figure 2A-C), demonstrating plastidic localization of $Z m T S A$. In contrast, $Z m$ TSAlike-GFP was localized in the cytosol (Figure 2D-F).

\section{ZmTSA has tryptophan synthase $\alpha$ activity}

We determined the kinetic parameters for the TS $\alpha$-reaction for the two candidates. Purified recombinant ZmTSA was tested for conversion of IGP to indole. A low, but clearly detectable IGP turnover $\left(\mathrm{K}_{\mathrm{cat}}=0.006 \mathrm{~s}^{-1}\right)$ was observed (Table 1 ). No $\alpha$-activity of recombinant $Z m$ TSAlike was detected in analogous experiments.

\section{Formation of a tryptophan synthase complex in vitro}

In bacteria $\alpha$ activity of the TS complex is two orders of magnitude higher than that of TSA alone. Therefore, $Z m$ TSA was allowed to interact with purified recombinant $\mathrm{ZmTSB} 1$ for $1 \mathrm{~h}$ at $4^{\circ} \mathrm{C}$ adding $60 \mathrm{mM}$ serine and $50 \mu \mathrm{M}$ pyridoxal phosphate. To investigate complex formation with ZmTSB1in vitro, the ZmTSA/ZmTSB1 mixture was subjected to size exclusion chromatography (Figure 3). $Z m$ TSA and ZmTSB1 formed a complex of approximately $160 \mathrm{kD}$ (Figure 3A) that according to SDS-PAGE analysis (data not shown) contained both proteins in a 1:1 stoichiometry. These results are consistent with formation of a $Z m \mathrm{TSA}_{2} Z m \mathrm{TSB}_{2}$ heterotetramer. The kinetic parameters of $Z m$ TSA, ZmTSB1, and ZmTSA/ZmTSB1 heteromers were determined (Table 1). Heteromerisation with ZmTSB1 resulted in a 32-fold increase of the catalytic efficiency of ZmTSA.

No interaction of ZmTSB1 with ZmTSAlike, BX1, or IGL was detectable. The native molecular masses of ZmTSAlike, BX1, and IGL were estimated by gel filtration to around $30 \mathrm{kD}$, indicating that these proteins were monomers in solution (Figure $3 \mathrm{~B}$ and data not shown). ZmTSB1 apparently formed dimers of approximately $90 \mathrm{kD}$ (Figure $3 \mathrm{~B}, \mathrm{C})$. No prominent larger complexes were observed. $Z m$ TSAlike remained inactive with IGP as substrate also when the $\beta$-subunit was added to the preparation (Table $1)$. The experiment was repeated with thrombin digested proteins to exclude lack of complexation due to sterical hindrance caused by the His-tag yielding identical results (data not shown).

\section{Tryptophan synthase activity in leaf protein extracts}

To investigate, whether $\alpha_{2} \beta_{2}$ TS complexes are also formed in vivo, protein extracts of B73 wildtype maize and the mutant lines $b x 1, Z m t s b 1$, and $Z m t s b 2$ were separated by size exclusion chromatography. Individual fractions were 

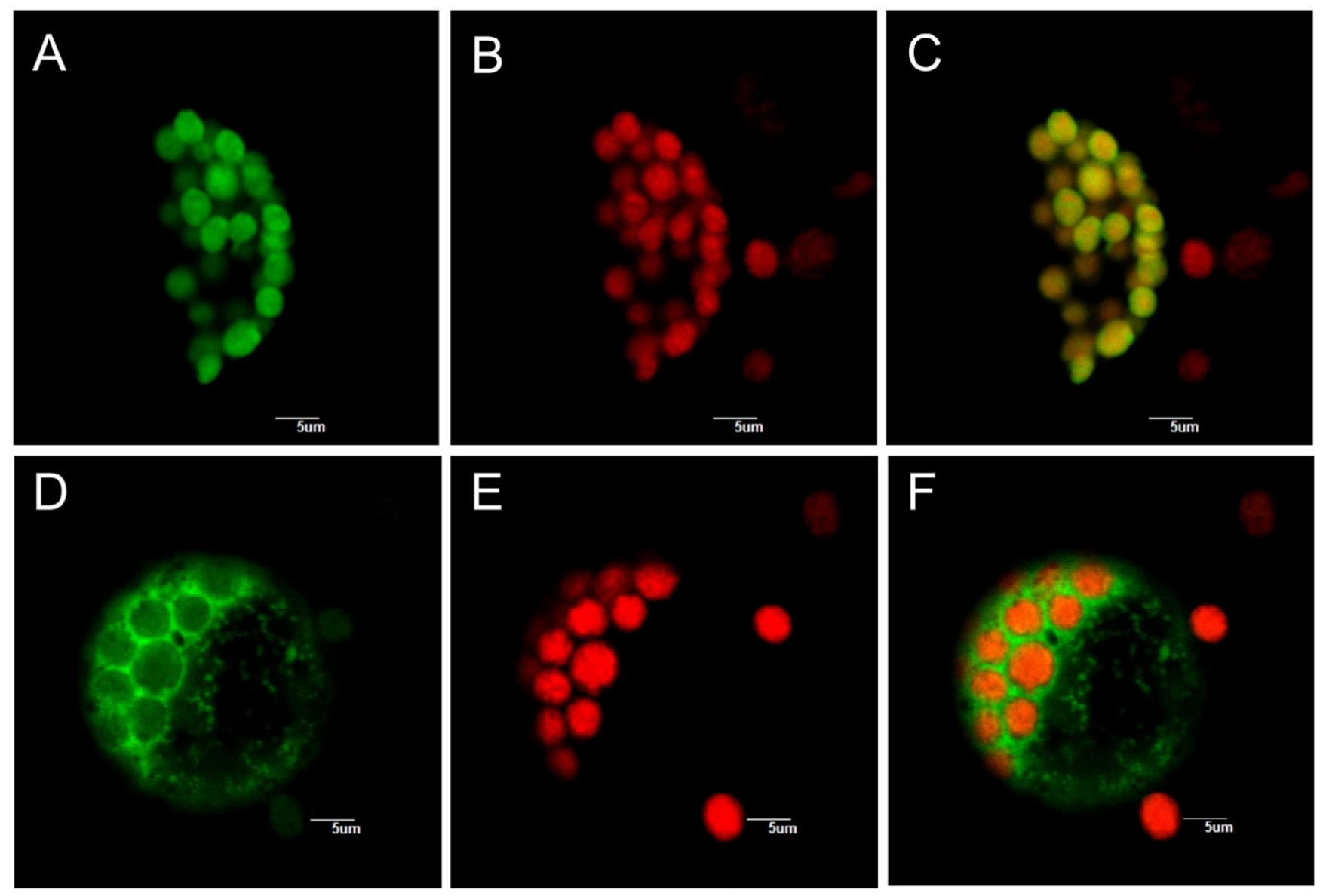

Figure 2

Subcellular localization of ZmTSA and ZmTSAlike fused to eGFP in maize cells. Analysis of maize mesophyll protoplasts transiently expressing ZmTSA::eGFP (A-C) or ZmTSAlike::eGFP (D-F). A, D: GFP fluorescence; B, E: Red chlorophyll autofluorescence in chloroplasts; C, F: Merged images.

tested for conversion of IGP to indole + glyceraldehyde-3phosphate ( $\alpha$ reaction) and of indole + serine to tryptophan ( $\beta$ reaction) (Figure 4$)$. In a fraction representing proteins of approx. $160 \mathrm{kD}$ both $\alpha$ - and $\beta$-activity was detected (app. $\mathrm{K}_{\mathrm{M}}{ }^{\mathrm{IGP}}=47 \pm 7 \mu \mathrm{M}$; app. $\mathrm{K}_{\mathrm{M}}$ indole $=5 \pm 2 \mu \mathrm{M}$, B73). This fraction was as well capable of the total $(\alpha \beta)$ TS reaction in all genotypes tested (IGP to tryptophan turnover rates of 96 to $\left.122 \mathrm{pmol} \mathrm{mg}^{-1} \mathrm{~min}^{-1}\right)$. $\beta$-Activity was also clearly detected in the fraction of approx. $90 \mathrm{kD}$ proteins, the size of putative $\beta$-dimers. The Zmtsb1 Zmtsb2 (orp1 orp2) double mutant is devoid of $\beta$-activity and shows severe growth defects [15]. Here, the respective single mutants Zmtsb1 (orp1 +/orp1 orp2) and Zmtsb2 (orp1 orp2/+ orp2) were tested and each yielded $\beta$-activity in both the $90 \mathrm{kD}$ and the $160 \mathrm{kD}$ complex fractions (Figure $4 \mathrm{D})$. This indicates that ZmTSB1 and ZmTSB2 are functionally redundant and may both form active $\beta$-dimers as well as active $\alpha \beta \beta \alpha$ TS complexes. In extracts from B73 wildtype, as well as Zmtsb1 or Zmtsb2 mutants a second $\alpha$ activity peak was determined in a fraction of approxi- mately $30 \mathrm{kD}$, corresponding to the monomer size of TSA homologs. In extracts of $b x 1$ mutants this activity was not present, indicating that monomeric $\alpha$-activity in leaves is predominantly due to activity of BX1 enzyme.

\section{ZmTSA is a component of the tryptophan synthase complex in maize}

To identify constituents of the $160 \mathrm{kD}$ TS complex in planta a mass-spectrometry-based approach was applied. Sequence qualifying peptides, i.e. peptides allowing annotation, were obtained for ZmTSA, ZmTSAlike, BX1, IGL, and ZmTSB1 by the analysis of tryptic digests of recombinant proteins using liquid chromatography with time-of-flight mass spectrometry coupled by electrospray ionisation (LC-ESI-ToF-MS). The resulting detection signals of peptides were compared with theoretically expected tryptic peptide masses [see Additional files 3 and 4]. $46.0 \%$ of the total sequence was covered for $Z m T S A$, $36.5 \%$ for $Z m$ TSAlike, $40.4 \%$ for $Z m T S B 1,50.0 \%$ for BX1, and $56.9 \%$ for IGL. 
Table I: Kinetic parameters of Zea mays tryptophan synthase and comparison with characterized homologs.

\begin{tabular}{|c|c|c|c|c|c|}
\hline Reaction & Recombinant Enzyme(s) & Substrate & $K_{M}(\mu M)$ & $\mathrm{k}_{\text {cat }}\left(\mathrm{s}^{-1}\right)$ & $\mathrm{k}_{\mathrm{cat}} / \mathrm{K}_{\mathrm{M}}\left(\mathrm{mM}^{-1} \mathrm{~s}^{-1}\right)$ \\
\hline$\alpha$ & ZmTSA & IGP & $458 \pm 94$ & $0.006 \pm 0.002$ & 0.013 \\
\hline$\alpha$ & $Z m T S A+Z m T S B I$ & IGP & $52 \pm 6$ & $0.019 \pm 0.004$ & 0.37 \\
\hline$\beta$ & ZmTSBI & Indole & $24 \pm 4$ & $0.29 \pm 0.04$ & 12.1 \\
\hline$\beta$ & $Z m T S A+Z m T S B I$ & Indole & $28 \pm 6$ & $0.44 \pm 0.07$ & 15.7 \\
\hline$\alpha \beta$ & $Z m T S A+Z m T S B I$ & IGP & $47 \pm 9$ & $0.45 \pm 0.06$ & 9.6 \\
\hline$\alpha$ & ZmTSAlike & IGP & n. d. & n. d. & n. d. \\
\hline$\alpha$ & ZmTSAlike+ZmTSBI & IGP & n. d. & n. d. & n. d. \\
\hline$\alpha$ & BXI [18] & IGP & 13 & 2.8 & 215 \\
\hline$\alpha$ & IGL [17] & IGP & 100 & 2.3 & 23 \\
\hline$\alpha$ & EcTSA I) & IGP & 480 & 0.002 & 0.004 \\
\hline$\alpha$ & $E c T S A+E c T S B$ & IGP & 27 & 0.2 & 7.4 \\
\hline$\alpha$ & StTSA + StTSB 2) & IGP & 100 & 0.14 & 1.4 \\
\hline$\beta$ & StTSA + StTSB 2) & Indole & 15 & 3.6 & 240 \\
\hline$\alpha \beta$ & $S t T S A+S t T S B$ 2) & IGP & 20 & 3 & 150 \\
\hline
\end{tabular}

I) [3I], Ec: E. coli.

2) [35], St: S. typhimurium.

n. d.: For ZmTSAlike no IGP turnover was detected.

To identify the active $\alpha$-subunit of the TS complex in maize, TS activity was partially purified from leaf extracts by subsequent ion exchange and size exclusion chromatography. The $160 \mathrm{kD}$ protein fraction was concentrated and separated by SDS-PAGE. Proteins between approx. 25 $\mathrm{kD}$ (smaller than TSA size) and $60 \mathrm{kD}$ (larger than TSB size) were cut out of the gel. A tryptic digest of these proteins was analyzed by LC-ESI-ToF-MS and surveyed for peptides sequence qualifying for ZmTSA, ZmTSAlike, BX1, IGL, and ZmTSB1.

Four peptides characteristic for ZmTSA were present as major peptide signals in this tryptic digest of the $160 \mathrm{kD}$ fraction containing active TS (Table 2, Figure 5). The probability for a specific random dodeca-peptide, such as e.g. identified GTTFEDVISMVK is in the order of approximately $10^{-15}$. Therefore, ZmTSA was conclusively identified as component of a maize TS complex. No peptides specific for ZmTSAlike, BX1, or IGL were detected [see Additional file 3]. The peptides ADGTGPLIYLK and DATSEAIR were identified, which could be assigned to either of the highly similar active ZmTSB isoforms. For $Z m T S B 1$ the specific peptide QALNVFR was identified. No $Z m T S B 2$ specific peptide was clearly assigned. However, based on Zmtsb1 mutant analysis (Figure 4) it is very likely that also ZmTSB2 is present in TS complexes in vivo. In summary, ZmTSA and ZmTSB1 were identified by LC-ESIToF-MSas constituents of TS complexes.

\section{Discussion}

Evidence for physical interaction of tryptophan synthase $\alpha$ and $\beta$ subunits in plants was provided by immunoaffinity chromatography for Arabidopsis [14] and by size exclusion chromatography for maize (this study). For the identification of the maize tryptophan synthase components in vivo, specific sequence qualifying peptides were assigned by LC-MS. This approach allows the analysis of enzyme complexes that are not sufficiently stable for application of a larger variety of chromatographic separations, necessary for purification to homogeneity. Applying this method, ZmTSA was identified as $\alpha$-subunit of a tryptophan synthase complex.

The apparent molecular weight strongly indicates that in maize tryptophan synthase is functional as $\alpha \beta \beta \alpha$ heterotetramer, similar as in bacteria [30,31]. In maize ZmTSA is the principal $\alpha$-subunit of the complex. Catalytic efficiency of ZmTSA was enhanced more than 30 -fold by interaction with the $\beta$-subunit (Table 1 ). Such activating interaction between $\alpha$ - and $\beta$-subunit is also well known from bacteria like E. coli (Table 1). In E. coli this activation was mutual, i.e. $\beta$-activity strongly increased upon formation of an $\alpha_{2} \beta_{2}$ TS complex [32]. In contrast, no significant activation of the maize $\beta$-subunit by $Z m$ TSA was observed (Table 1). The reason for this difference between the bacterial and plant enzyme is not known.

In maize, ancestral TSAs have been recruited for secondary metabolism. The TSA homologs BX1 and IGL catalyze the formation of indole, which functions as DIMBOA precursor or volatile signal [17-19] (Table 1) and BX1 monomer activity was observed in leaf extracts (Figure 4). In addition, TSB dimers that have been observed in leaf extracts (Figure 4) and in vitro (Figure 3), which possibly function in salvage of indole by its conversion to tryptophan. It remains open, whether a mechanism involving BX1 mon- 

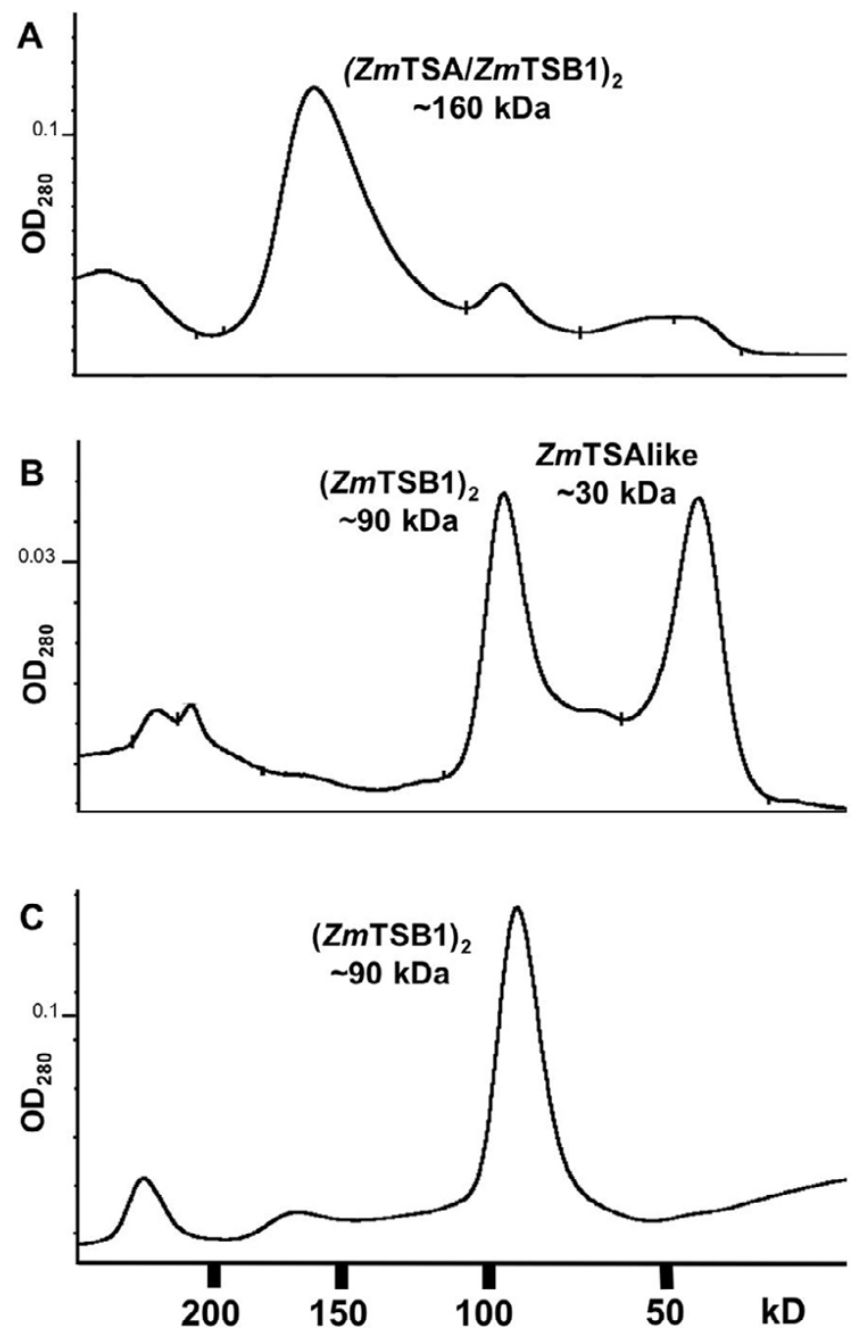

Figure 3

In vitro complex formation. Combinations of recombinant proteins, $0.5 \mathrm{mg}$ each, were allowed to assemble I h at $4^{\circ} \mathrm{C}$. An aliquot each was analyzed by size exclusion chromatography and the elution of protein was monitored by absorption at $280 \mathrm{~nm}$. A: ZmTSA + ZmTSBI, the retention volume of the major peak corresponds the size of an $\alpha_{2} \beta_{2}$ tetramer. B: ZmTSAlike $+Z m T S B I$, two peaks corresponding an $\alpha$ monomer and a $\beta_{2}$ dimer are observed. C: $Z m T S B I$ without addition of a TSA homolog; putative $\beta_{2}$ dimers are formed.

omer and TSB dimer contributes significantly to the total metabolic flux towards tryptophan. The $b x 1$ mutant and the $b x 1$ igl double mutant (M. Frey, unpublished data) are fully viable; therefore this process is not essential at any stage of development.

We propose that, despite the availability of the highly active monomers BX1 and IGL, in maize tryptophan is predominantly synthesized through a tryptophan syn-
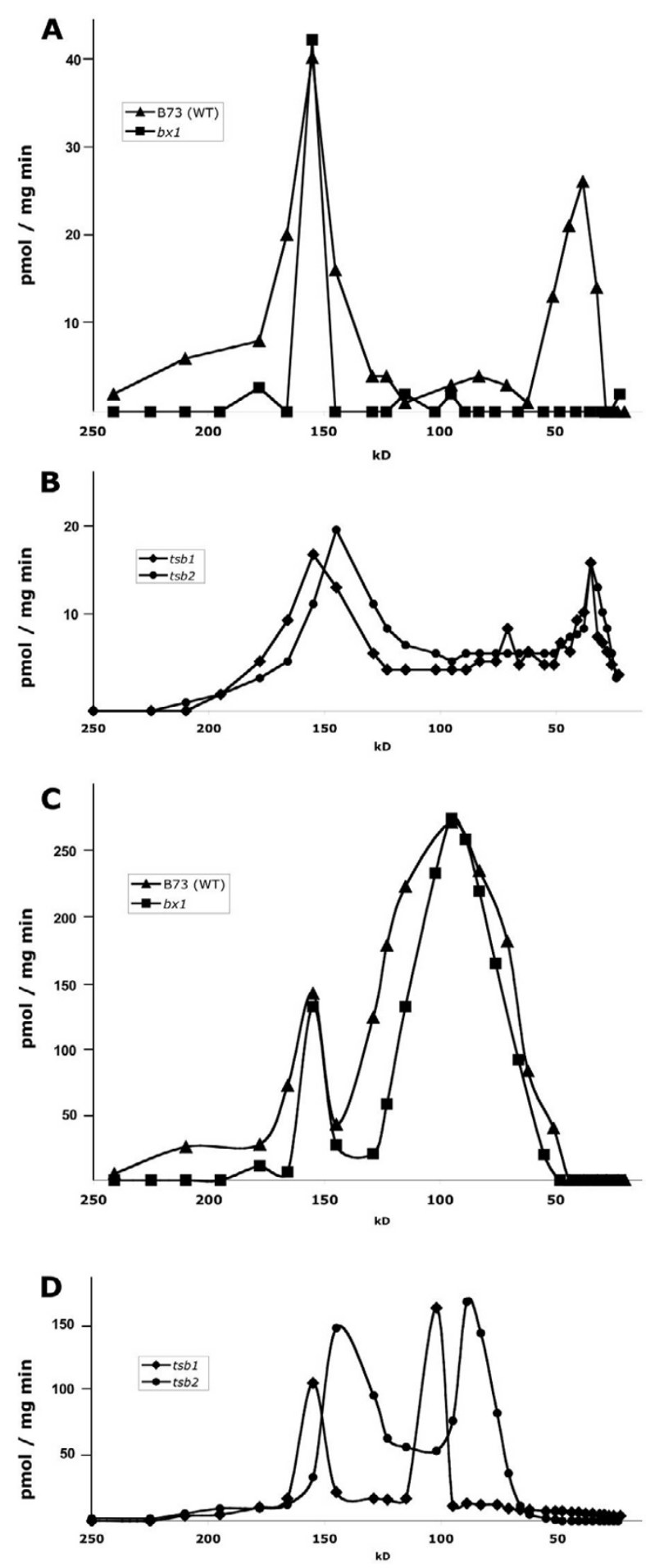

Figure 4

Determination of enzymatic activities in leaf extracts fractionized by size exclusion chromatography. Formation of indole from IGP ( $\alpha$-reaction, A, B) and of tryptophan from indole + serine $(\beta$-reaction, $C, D)$ was quantified. The wildtype line $B 73, b x I$ mutant $(A, C)$, and tsb I and tsb2 mutants (B, D) were analyzed. 


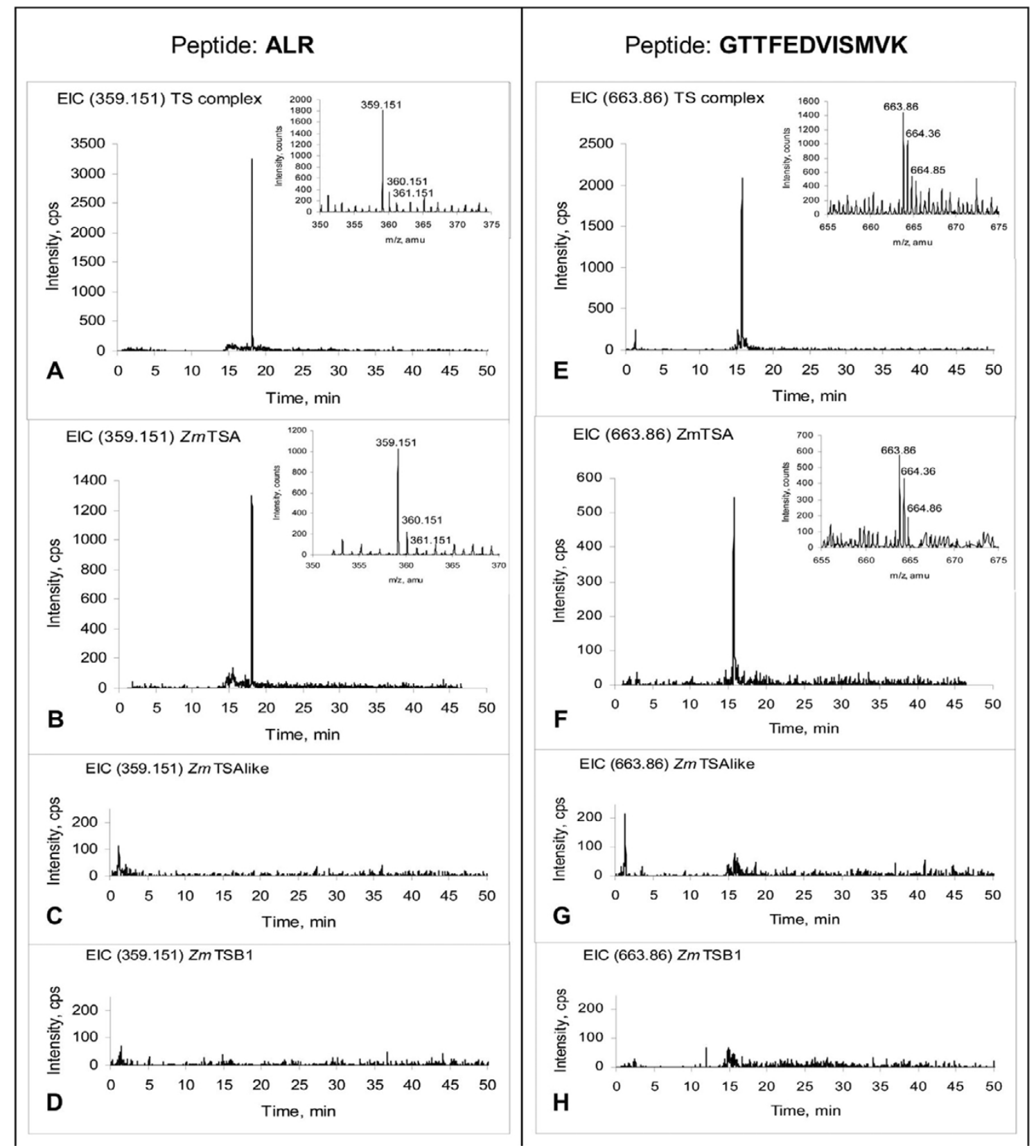

Figure 5

Identification of ZmTSA as component of the tryptophan synthase complex. The approach is exemplified by the peptides ALR (A-D, $\mathrm{m} / \mathrm{z}=359.15 \mathrm{I})$ and GTTFEDVISMVK $(\mathrm{E}-\mathrm{H}, \mathrm{m} / \mathrm{z}=663.860)$. These fragments are characteristic for $Z m$ TSA $(B, F)$ and were absent in ZmTSAlike $(C, G)$ and $Z m T S B I(D, H)$. Both fragments were identified in a trypsin hydrolysate of the active tryptophan synthase fraction $(A, E)$. The peptide and the corresponding ${ }^{13} \mathrm{C} /{ }^{34} \mathrm{~S}$ isotopic peaks were detected (inserts in $A, B, E, F)$.

Table 2: ZmTSA sequence qualifying peptides identified in a tryptic digest of tryptophan synthase partially purified from leaves.

\begin{tabular}{|c|c|c|c|c|c|}
\hline ret. time (min) & $\mathrm{m} / \mathrm{z}$ & charge & EIC intensity & calc. mass & peptide \\
\hline 15.1 & 371.239 & $1+$ & $5.60 \mathrm{E}+03$ & 370.449 & AALP \\
\hline 15.5 & 687.361 & $2+$ & $7.00 \mathrm{E}+04$ & 1373.480 & TLEEAASPEEGLK \\
\hline 15.7 & 663.860 & $2+$ & $5.00 \mathrm{E}+02$ & 1326.528 & GTTFEDVISMVK \\
\hline 18.2 & 359.151 & $1+$ & $1.30 \mathrm{E}+03$ & 359.440 & ALR \\
\hline
\end{tabular}

EIC: Extracted ion chromatogram 
thase complex containing ZmTSA and ZmTSB1 or $Z m$ TSB2, respectively. Probably this complex has been retained during evolution for tryptophan synthesis, as it enables substrate channelling and allosteric regulation. Knockout mutants could serve as ultimate proof for ZmTSA being essential. Therefore we have extensively screened public databases as well as the large Pioneer HiBred TUSC collection for $M u$-transposon insertion mutants [33] in ZmTSA. However, no insertion alleles were identified. It remains open, whether $Z m$ tsa knockout mutants are lethal.

Based on import studies, subcellular fractionation, and target sequence prediction, it is suggested that in plants the biosynthesis of aromatic amino acids is predominantly localized in plastids (for review, see [29]). Consistent with these data ZmTSA contains a chloroplast targeting sequence and ZmTSA::GFP fusion proteins were targeted to the plastid (Figure 2). Interestingly, the TSA homolog ZmTSAlike lacks such a transit peptide and $Z m \mathrm{~T}$ SAlike::GFP fusion proteins were located in the cytosol (Figure 2). It has been debated whether the biosynthesis of aromatic amino acids is also partially active in the cytoplasm, as e.g. a cytoplasmic isoform of chorismate mutase is expressed in Arabidopsis [34]. As recombinant ZmTSAlike, expressed in E. coli, did not show any $\alpha$-activity it remains unclear, whether ZmTSAlike functions as cytosolic TSA isoform. ZmTSAlike might either require specific conditions and modifications or it has an unknown function in plant metabolism.

\section{Conclusion}

Four TSA homologs exist in maize. Only one of these isoforms, ZmTSA, is involved in the formation of a tryptophan synthase complex. Based on our data and previous results for Arabidopsis thaliana we propose that a ubiquitous tryptophan synthase complex is responsible for tryptophan formation in angiosperms, like in fungi and bacteria.

\section{Abbreviations}

ACN: acetonitrile; bx1: benzoxazinless1; GAPDH: glyceraldehyde-3-phosphate dehydrogenase; IGL: indole-3-glycerol phosphate lyase; IGP: indole-3-glycerol phosphate; TSA: tryptophan synthase alpha subunit; TSB: tryptophan synthase beta subunit; wap: weeks after pollination.

\section{Availability and requirements}

Maize genomic database: http://www.maizegdb.org

\section{Authors' contributions}

VK designed, conducted, and analyzed the majority of experiments and supported drafting the manuscript. LW carried out the LC-MS analysis. AF analyzed the sub-cellular localisation of proteins. TL designed and supervised the LC-MS analysis and interpretation. MF conducted transcription analysis, supervised localisation studies and cloning, and revised the manuscript. AG conceptualised the project, coordinated the group, and revised the manuscript. EG supervised the project, supported experiment design and analysis, and wrote the draft of the manuscript. All authors read and approved the manuscript.

\section{Additional material}

\section{Additional file 1}

Figure SF1: Amino acid sequence alignment of the maize TSA homologs (ClustalW). Transit peptides are depicted in italics. For ZmTSA and IGL they were predicted using TargetP [23], for BX1 it was determined experimentally [36].

Click here for file

[http://www.biomedcentral.com/content/supplementary/14712229-8-44-S1.doc]

\section{Additional file 2}

Table S1: Transcript levels of ZmTSA and ZmTSAlike relative to GAPDH in RNA preparations from different tissues.

Click here for file

[http://www.biomedcentral.com/content/supplementary/14712229-8-44-S2.doc]

\section{Additional file 3}

Table S2: MS-signals yielding identification of sequence qualifying peptides of recombinant ZmTSA, ZmTSAlike, IGL, BX1, and ZmTSB1. Click here for file

[http://www.biomedcentral.com/content/supplementary/14712229-8-44-S3.doc]

\section{Additional file 4}

Table S3: LC/MSD TOF analysis of trypsin digested recombinant ZmTSA, ZmTSAlike, IGL, BX1, and TSB1; list of major signals. Click here for file

[http://www.biomedcentral.com/content/supplementary/14712229-8-44-S4.xls]

\section{Acknowledgements}

We thank U. Genschel for comments on the manuscript and K. Fütterer and S. Grosse for practical assistance. Agilent Technologies is acknowledged for the loan of the HPLC system. This work has been supported by the Deutsche Forschungsgemeinschaft.

\section{References}

I. Gibbon BC, Larkins BA: Molecular genetic approaches to developing quality protein maize. Trends Genet 2005, 2 I (4):227-233.

2. Huang S, Frizzi A, Florida CA, Kruger DE, Luethy MH: High lysine and high tryptophan transgenic maize resulting from the reduction of both 19- and 22-kD alpha-zeins. Plant Mol Biol 2006, 6 I (3):525-535.

3. Facchini PJ: Alkaloid biosynthesis in plants: biochemistry, cell biology, molecular regulation, and metabolic engineering applications. Annu Rev Plant Physiol Plant Mol Biol 200I, 52:29-66. 
4. Kriechbaumer $V$ Glawischnig, E: Auxin biosynthesis within the network of tryptophan metabolism. Journal of Nano \& Bio Tech 2005, 2:55-58.

5. Ljung K, Hull AK, Kowalczyk M, Marchant A, Celenza J, Cohen JD, Sandberg G: Biosynthesis, conjugation, catabolism and homeostasis of indole-3-acetic acid in Arabidopsis thaliana. Plant Mol Biol 2002, 49(3-4):249-272.

6. Crawford IP Yanofsky, C: On the separation of the tryptophan synthetase of Escherichia coli into two protein components. Proceedings of the National Acadademy of Science, USA 1958, 44: I I6I-II70.

7. Miles EW: Tryptophan synthase: a multienzyme complex with an intramolecular tunnel. Chem Rec 2002/03/15 edition. 2001, I(2): $|40-| 5 \mid$.

8. Miles EW: Tryptophan synthase: structure, function, and subunit interaction. Adv Enzymol Relat Areas Mol Biol 1979, 49: I 27- 186.

9. Leopoldseder S, Hettwer S, Sterner R: Evolution of multi-enzyme complexes: the case of tryptophan synthase. Biochemistry 2006 45(47): $|4|||-|4| \mid 9$.

10. Matchett WH, DeMoss JA: The subunit structure of tryptophan synthase from Neurospora crassa. J Biol Chem 1975, 250(8):294l-2946.

I I. Last RL, Bissinger PH, Mahoney DJ, Radwanski ER, Fink GR: Tryptophan mutants in Arabidopsis: the consequences of duplicated tryptophan synthase beta genes. Plant Cell 1991, 3(4):345-358

12. Radwanski ER, Barczak AJ, Last RL: Characterization of tryptophan synthase alpha subunit mutants of Arabidopsis thaliana. Mol Gen Genet 1996, 253(3):353-361.

13. Zhao J, Last RL: Immunological characterization and chloroplast localization of the tryptophan biosynthetic enzymes of the flowering plant Arabidopsis thaliana. J Biol Chem 1995, 270(I I):608I-6087.

14. Radwanski ER, Zhao J, Last RL: Arabidopsis thaliana tryptophan synthase alpha: gene cloning, expression, and subunit interaction. Mol Gen Genet 1995, 248(6):657-667.

15. Wright AD, Moehlenkamp CA, Perrot GH, Neuffer MG, Cone KC: The maize auxotrophic mutant orange pericarp is defective in duplicate genes for tryptophan synthase beta. Plant Cell 1992, 4(6):7||-7|9.

16. Wright AD, Sampson MB, Neuffer MG, Michalczuk L, Slovin JP, Cohen JD: Indole-3-acetic acid biosynthesis in the mutant maize orange pericarp, a tryptophan auxotroph. Science 1991, 254(5034):998-1000.

17. Frey M, Stettner C, Pare PW, Schmelz EA, Tumlinson JH, Gierl A: An herbivore elicitor activates the gene for indole emission in maize. Proc Natl Acad Sci U S A 2000, 97(26): |480| - |4806.

18. Frey M, Chomet P, Glawischnig E, Stettner C, Grün S, Winklmair A, Eisenreich W, Bacher A, Meeley RB, Briggs SP, Simcox K, Gierl A: Analysis of a chemical plant defense mechanism in grasses. Science 1997, 277(5326):696-699.

19. Kulik V, Hartmann E, Weyand M, Frey M, Gierl A, Niks D, Dunn MF, Schlichting I: On the structural basis of the catalytic mechanism and the regulation of the alpha subunit of tryptophan synthase from Salmonella typhimurium and BXI from maize, two evolutionarily related enzymes. J Mol Biol 2005, 352(3):608-620.

20. Frey M, Spiteller D, Boland W, Gierl A: Transcriptional activation of IgI, the gene for indole formation in Zea mays: a structureactivity study with elicitor-active $\mathbf{N}$-acyl glutamines from insects. Phytochemistry 2004, 65(8): 1047-1055.

21. Hamilton RH: A corn mutant deficient in 2,4-dihydroxy-7methoxy-I,4-benzoxazin-3-one with an altered tolerance of atrazine. Weeds 1964, 12:27-30.

22. Bannai H, Tamada Y, Maruyama O, Nakai K, Miyano S: Extensive feature detection of $\mathbf{N}$-terminal protein sorting signals. Bioinformatics 2002/02/16 edition. 2002, 18(2):298-305.

23. Emanuelsson $\mathrm{O}$, Nielsen $\mathrm{H}$, Brunak $\mathrm{S}$, von Heijne $\mathrm{G}$ : Predicting subcellular localization of proteins based on their $\mathbf{N}$-terminal amino acid sequence. I Mol Biol 2000/07//3 edition. 2000, 300(4): $1005-1016$.

24. Creighton TE: A steady-state kinetic investigation of the reaction mechanism of the tryptophan synthetase of Escherichia coli. Eur J Biochem 1970, I3(I): I-10.
25. Neuhoff V: Clear background and highly sensitive protein staining with Coomassie Blue dyes in polyacrylamide gels: A systemic analysis. Electrophoresis 1985, 6:427-448.

26. Cutler SR Ehrhardt, DW, Griffitts, JS, Somerville, CR: GFP::CDNA fusions enable visualization of subcellular structures in cells of Arabidopsis at a high frequency. Proceedings of the National Acadademy of Science, USA 2000, 97:3718-3723.

27. Sheen J: Molecular mechanisms underlying the differential expression of maize pyruvate, orthophosphate dikinase genes. Plant Cell I99I, 3(3):225-245.

28. Sheen J: Metabolic repression of transcription in higher plants. Plant Cell 1990, 2(10): 1027-1038.

29. Schmid J Amrhein, N: Molecular organization of the shikimate pathway in higher plants. Phytochemistry 1995, 39:737-749.

30. Kirschner K, Lane AN, Strasser AW: Reciprocal communication between the lyase and synthase active sites of the tryptophan synthase bienzyme complex. Biochemistry 1991, 30(2):472-478.

31. Weischet WO, Kirschner K: Steady-state kinetic studies of the synthesis of indoleglycerol phosphate catalyzed by the alpha subunit of tryptophan synthase from Escherichia coli. Comparison with the alpha2 beta2-complex. Eur J Biochem 1976, 65(2):375-385

32. Lane AN, Kirschner K: The catalytic mechanism of tryptophan synthase from Escherichia coli. Kinetics of the reaction of indole with the enzyme--L-serine complexes. Eur J Biochem 1983, I 29(3):57|-582.

33. Mena M, Ambrose BA, Meeley RB, Briggs SP, Yanofsky MF, Schmidt $\mathrm{RJ}$ : Diversification of $\mathrm{C}$-function activity in maize flower development. Science 1996, 274(5292): I537-I540.

34. Eberhard J, Ehrler TT, Epple P, Felix G, Raesecke HR, Amrhein N, Schmid J: Cytosolic and plastidic chorismate mutase isozymes from Arabidopsis thaliana: molecular characterization and enzymatic properties. Plant J I996/II/0I edition. I996, I0(5):815-82I.

35. Kawasaki H, Bauerle R, Zon G, Ahmed SA, Miles EW: Site-specific mutagenesis of the alpha subunit of tryptophan synthase from Salmonella typhimurium. Changing arginine 179 to leucine alters the reciprocal transmission of substrateinduced conformational changes between the alpha and beta 2 subunits. J Biol Chem 1987, 262(22): 10678-10683.

36. Stettner C: DIMBOA-Biosynthese in Mais: Isolierung und funktionelle Charakterisierung des BxI-Gens. Lehrstuhl für Genetik, TU München; 1998.

Publish with Bio Med Central and every scientist can read your work free of charge

"BioMed Central will be the most significant development for disseminating the results of biomedical research in our lifetime. "

Sir Paul Nurse, Cancer Research UK

Your research papers will be:

- available free of charge to the entire biomedical community

- peer reviewed and published immediately upon acceptance

- cited in PubMed and archived on PubMed Central

- yours - you keep the copyright
BioMedcentral 